\title{
Capillariid nematodes in Brazilian turkeys, Meleagris gallopavo (Galliformes, Phasianidae): pathology induced by Baruscapillaria obsignata and Eucoleus annulatus (Trichinelloidea, Capillariidae)
}

\author{
Roberto Magalhães Pinto/ ${ }^{+}$, Beatriz Brener, Rogério Tortelly¹, Rodrigo Caldas Menezes², \\ Luís Cláudio Muniz-Pereira
}

Laboratório de Helmintos Parasitos de Vertebrados, Instituto Oswaldo Cruz-Fiocruz, Av. Brasil 4365, 21040-900 Rio de Janeiro, RJ, Brasil 'Departamento de Patologia, Faculdade de Veterinária, Universidade Federal Fluminense, Niterói, RJ, Brasil

${ }^{2}$ Instituto de Pesquisas Evandro Chagas-Fiocruz, Rio de Janeiro, RJ, Brasil

The pathology induced in turkeys (Meleagris gallopavo) by two capillariid nematodes, Baruscapillaria obsignata and Eucoleus annulatus is described together with data on prevalences, mean infection and range of worm burdens. B. obsignata occurred with a prevalence of $72.5 \%$ in the 40 examined hosts in a range of 2-461 nematodes and a mean intensity of 68.6, whereas E. annulatus was present in $2.5 \%$ of the animals, with a total amount of five recovered parasites. Gross lesions were not observed in the parasitized birds. Lesions due to B. obsignata mainly consisted of the thickening of intestinal villi with a mild mixed inflammatory infiltrate with the presence of mononuclear cells and heterophils. The lesions induced by E. annulatus were represented by foci of inflammatory infiltrate with heterophils in the crop epithelium and esophagus of a single infected female. These are the first pathological findings related to the presence of capillariid worms in turkeys to be reported in Brazil so far. Capillaria anatis, although present, was not pathogenic to the investigated turkeys.

Key words: Baruscapillaria obsignata - Capillaria anatis - Eucoleus annulatus - Meleagris gallopavo - turkeys - pathology

Data on helminths of turkeys (Meleagris gallopavo Linnaeus, 1758) are relatively very few and thus, the action of the parasitism affecting these hosts is little known. In Brazil, investigations related to the pathology induced by helminths in turkeys are restricted to those of the pioneer paper by Barretto and Mies-Filho (1942) and more recently to the results reported by Brener et al. (2006a, b), describing the pathogenic action of the trematode Paratanaisia bragai, the nematodes Cheilospirura hamulosa, Heterakis gallinarum and the protozoan Histomas meleagridis infecting this avian host. In despite of representing the most frequent and relevant worms to parasitize Galliformes with reports worldwide, the capillariid nematodes (formerly included among the Trichiuroidea) were only listed in Brazil, occurring in several avian hosts, including turkeys, with no data on associated pathology (Costa et al. 1986, Vicente et al. 1995), except for the results obtained by Pinto et al. (2004) related to the pathological changes observed in pheasants infected with Eucoleus perforans, Eucoleus annulatus [= Capillaria annulata $]$, Capillaria phasianina and Baruscapillaria obsignata $[=$ Capillaria obsignata $]$.Interestingly, gross and microscopic lesions were absent in the ring-necked pheasants parasitized with E. annulatus

\footnotetext{
+ Corresponding author: rmpinto@ioc.fiocruz.br Received 9 February 2008 Accepted 24 April 2008
}

and B. obsignata. This paper deals with the first data on the induced pathology of the two capillariid nematode species B. obsignata (Madsen, 1945) Moravec, 1982 and E. annulatus (Molin, 1858) Lopez-Neyra, 1947 in Brazilian turkeys. Capillaria anatis (Schrank, 1790) Travassos, 1915, although present, was not pathogenic to the investigated birds.

\section{MATERIALS AND METHODS}

From May 2004 to October 2005, 40 adult turkeys, 19 males, 21 females, weighting between 950-8,870 g, obtained from backyard flocks of different states and cities of Brazil were investigated for helminths in the digestive tract: a) Minas Gerais (19 animals), namely Can-

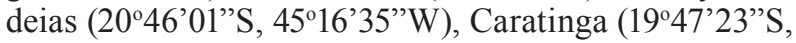
$\left.42^{\circ} 08^{\prime} 21^{\prime \prime} \mathrm{W}\right)$, Juizde Fora (21 ${ }^{\circ} 45^{\prime} 51^{\prime \prime} \mathrm{S}, 43^{\circ} 21^{\prime}$ '01'”W), Teix-

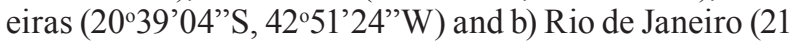
animals), namely Cantagalo ( $21^{\circ} 58^{\prime} 52^{\prime \prime} \mathrm{S}, 42^{\circ} 22^{\prime} 05^{\prime} \mathrm{W}$ ),

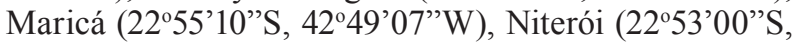
$\left.43^{\circ} 06^{\prime} 13^{\prime \prime} \mathrm{W}\right)$ [Várzea das Moças district], Piraí

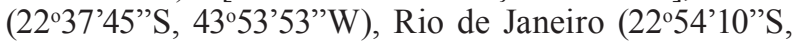
$43^{\circ} 12^{\prime} 27^{\prime \prime} \mathrm{W}$ ) [Campo Grande district], Teresópolis $\left(22^{\circ} 24^{\prime} 44^{\prime \prime} \mathrm{S}, 42^{\circ} 57^{\prime} 56^{\prime \prime} \mathrm{W}\right)$. After individual clinical evaluation, birds were killed and submitted to necropsy in accordance to the technique of Zander et al. (1997). Organs were opened in Petri dishes containing $0.85 \% \mathrm{NaCl}$ solution. Nematodes were fixed in hot AFA (ethanol $70 \%$, $93 \mathrm{ml}$; formaldehyde, $5 \mathrm{ml}$; acetic acid, $2 \mathrm{ml}$ ). Sections of the parasitized organs were removed and immediately fixed in $10 \%$ buffered formalin, to be further routinely processed for paraffin embedding. Five micrometers thick sections were stained with hematoxylin and eosin (HE). The recovered nematodes were counted under a 
stereomicroscope and after, stained with alcoholic chloride carmine, dehydrated in an ethanol series $(70 \%$ $100 \%$ ), cleared in phenol and mounted in balsam. Helminths were deposited in the Helminthological Collection of the Instituto Oswaldo Cruz (CHIOC). Classification of nematodes follows Vicente et al. (1995). Micrographs were obtained in a Zeiss Axiophot brightfield microscope. The development of this study has been authorized by the Ethics Committee on Animal Use (CEUAFiocruz, no. P0095-01).

\section{RESULTS}

Thirty-three $(82.5 \%)$ out of 40 turkeys were positive for capillariid worms. Gross lesions were not detected in animals either infected with $B$. obsignata or E. annulatus.

$B$. obsignata was mostly found in the small intestine and was observed in 29 turkeys $(72.5 \%)$ and in two out of these worms were also present in the large intestine. The mean intensity of infection was of 68.6 worms in a range of 2-461 parasites. The turkey with the highest worm burden (461) was an adult female specimen (from Rio de Janeiro, RJ), weighting 4,300 g, followed by younger animals, two males (from Niterói, RJ) weighting $950 \mathrm{~g}$ and $1,150 \mathrm{~g}$, with 314 and 197 worms, respectively. In the animal with the highest worm burden, it was observed, mainly in the area of the intestinal crypts, in addition to portions of the parasites among the villi, thickening of the villi, together with a mild mixed inflammatory infiltrate, in the presence of mononuclear cells and heterophils were also observed (Fig. 1). Studied material deposited in the CHIOC no. 36891 a-d (whole mounts).

Five specimens of $E$. anullatus were recovered in the upper digestive tract and in the crop of a single young female (from Maricá, RJ), weighting 1,500 g. This finding represented a prevalence of $2.5 \%$. Infiltrating heterophils were seen in the crop epithelium, with the presence of parasite eggs among these leucocytes that were filling tunnels lined with keratin (Fig. 2). In the esophagus, heterophils foci were observed, in the absence of eggs or parasite debris. Studied material was also deposited in the CHIOC no. 36894 a-d (whole mounts).

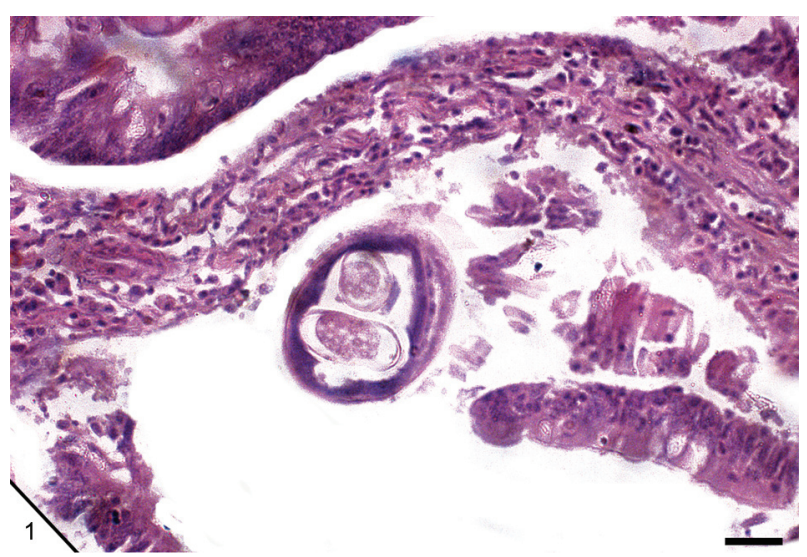

Fig. 1: histological section of the small intestine of Meleagris gallopavo showing a section of an adult female of Baruscapillaria obsignata with bioperculated eggs in utero among the villi together with a mild mixed inflammatory infiltrate in the mucosa. HE. Bar $=0.03 \mathrm{~mm}$.

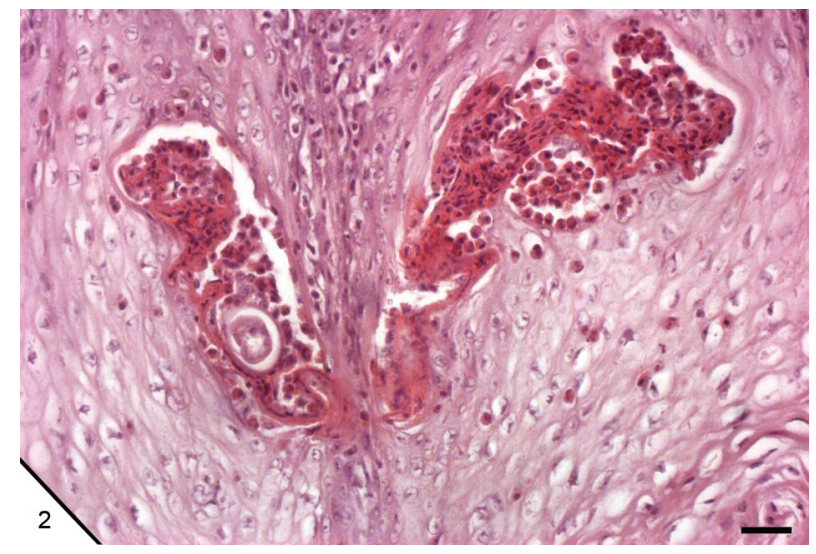

Fig. 2: histological section of the crop of Meleagris gallopavo parasitized with Eucoleus anullatus. Detail of a tunnel in the epithelium lined with keratin together with heterophils and an egg of the nematode. $\mathrm{HE}$. $\mathrm{Bar}=0.08 \mathrm{~mm}$.

C. anatis (Schrank, 1790) Travassos, 1915, although present in $22.5 \%$ of the animals, with a mean intensity of 31.8 and a range of infection of 16-91 worms, was not pathogenic to the investigated birds. Co-infections with B. obsignata and C. anatis were observed in $12.8 \%$ of the turkeys. The specimens were deposited in the CHIOC no. 36890 a-e (whole mounts).

\section{DISCUSSION}

The first data on the pathology induced by C. annulatus in turkeys were reported by Hung (1926), describing the results based on five animals that had died apparently due to the presence of the parasites. This is a study of the alterations of the aspect of the walls of esophagus and crop with early hyperemia and thickening of the esophageal lining, next to the mucosal areas of embedding parasites. In a subsequent phase, the lymphoid follicles increased, together with an extensive and severe wall thickening followed by loss of elasticity. In a late stage, the mucosa collapsed and there was the formation of a fibrinous pseudo-membrane that, interfering in the functions of the crop, forced the birds to avoid grains and ingest soft food, instead. Microscopically, these stages showed hyperemia and lymphocytary infiltrate, flaskshaped enlargement and necrosis of lymphoid follicles. A great amount of parasite eggs could be observed in the mucosa where the parasites deeply burrowed reaching the muscular layer.

Graham (1935) described similar lesions occurring in pheasants (Phasianus colchicus) except for a larger amount of plasmatic cells than lymphocytes. Also, it was suggested that the parasite penetration into the esophagus wall was stimulated by abnormal and poor dietary conditions of the hosts (Cram 1936).

The prevalence and the intensity of infection reported here for E. annulatus were low, similar to those reported for pheasants by Pinto et al. (2004) in Brazil and by Tampieri et al. (2005) in Europe. Although gross and microscopic alterations induced either by E. annulatus or B. obsignata were not described in studies of the former authors, there is the description of lesions caused by E. perforans in pheasants that are similar to those provoked by E. annulatus presently 
observed in turkeys and that consist of a mild esophagitis and epithelium elongated-lined (tunnels) of the crop lined with eosinophilic material, in the presence of cellular debris and eggs of the parasites.

These alterations, apparently had no effect for the feeding process of the birds, and the absence of clinical signs associated to the parasitism with E. annulatus observed here, are probably related to the low parasite burden ( 5 nematode specimens) harbored by the single infected turkey, what is in accordance with Pinto et al. (2004), since this nematode is known to be highly pathogenic to turkeys. According to Hurst et al. (1979) that reported to the death of 23 young (6-10 weeks) turkeys out of the 56 observed and infected with E. anullatus; the infection was the cause of inappetence, loss of weight and lethargy. Carcasses were emaciated and crops distended. The lesions in the crops were described as layer corrugations of the mucosa with a mild thickening evolving to a compact necrotic diphtheric membrane that covered the entire surface of the mucosa. A severe infection due to E. annulatus in the crop squamous epithelium of the animals was observed, in the presence of heterophils, lymphocytes and plasmocytes. Connective tissue and glands were affected as a result of inflammatory infiltrates and necrosis. The squamous epithelium was thickened and irregular spine-like projections on the surface were evident.

Data after Pinto et al. (2004) suggest that the tunnels formed by the migration of capillariid worms in the epithelium of the crop and esophagus of infected birds may promote the settlement of secondary infections that, intensifying the severity of the lesions, can cause the death of the host.

In the case of infections with B. obsignata, the only available data are those referring to drug assays to investigate the efficacy of the treatment of pigeons (Jha 1977, Zuchowska 1994, Ibrahim et al. 1995, Sridhar et al. 1999, Toro et al. 1999) geese, pheasants, and chickens (Enigk et al. 1973) most of them experimentally infected with this nematode species, without description of induced lesions. To our knowledge, this is the first reported histological lesions associated with B. obsignata in turkeys.

\section{REFERENCES}

Barretto JF, Mies-Filho A 1942. Primeiras observações sobre a presença de "Tamerlanea bragai" (Violantino Santos, 1934) nos rins de Meleagris gallopavo domestica, Ministério da Agricultura, Instituto de Biologia Animal, Rio de Janeiro, 3 pp.
Brener B, Tortelly R, Menezes RC, Muniz-Pereira LC, Pinto RM 2006a. Prevalence and pathology of the nematode Heterakis gallinarum, the trematode Paratanaisia bragai, and the protozoan Histomonas meleagridis in the turkey, Meleagris gallopavo. Mem Inst Oswaldo Cruz 101: 677-681.

Brener B, Tortelly R, Muniz-Pereira LC, Pinto RM 2006b. First report of Cheilospirura hamulosa (Diesing, 1851) (Nematoda, Acuarioidea) in turkeys, Meleagris gallopavo (L., 1758) (Aves, Phasianidae) in Brazil: prevalence and pathology. Arq Bras Med Vet Zootec 58: 287-290.

Costa HMA, Leite ACR, Guimarães MP, Lima WS 1986. Distribuição de helmintos parasitos dos animais domésticos no Brasil. Arq Bras Med Vet Zootec 38: 465-579.

Cram E 1936. Species of Capillaria parasitic in the upper digestive tract of birds. US Dept Agric Tech Bull 516: 1-27.

Enigk E, Dey-Hazra, Batke J 1973. Zur Wirksamkeit von Mebendazole bei Helminthosen von Huhn und Gans. Avian Pathol 2: 67-74.

Graham GL 1935. Capillaria infestations in New Jersey pheasants. J Parasitol 21: 61-62.

Hung SL 1926. Pathological lesions caused by Capillaria annulata. North Am Vet 7: 49-50.

Hurst GA, Turner LW, Tucker FS 1979. Capillariasis in penned wild turkeys. J Wildl Dis 15: 395-397.

Ibrahim AI, Hassanin HH, Aly SEM, Abdel-Aal AA 1995. A study on some parasitic affections in domestic pigeons in Ismalia province. Assiut Vet Med J 34: 153-161.

Jha GJ 1977. A note on Capillaria obsignata (Madan, 1945) in the naturally infected Jacobin pigeon. Indian J Vet Pathol 2: 42.

Pinto RM, Tortelly R, Menezes RC, Gomes DC 2004. Trichurid nematodes in ring-necked pheasants from backyard flocks of the State of Rio de Janeiro, Brazil: frequency and pathology. Mem Inst Oswaldo Cruz 99: 721-726.

Sridhar R, Sangaran A, Manohar BM 1999. A case of capillariasis in a pigeon. Cheiron 28: 81-82.

Tampieri MP, Galuppi R, Rugna G 2005. Survey on helminthofauna in pheasants from Eastern Europe. Parassitol 47: 241-245.

Toro H, Saucedo C, Borie C G, Alcaino H 1999. Health status of freeliving pigeons in the city of Santiago. Avian Pathol 28: 619-623.

Vicente JJ, Rodrigues HO, Gomes DC, Pinto RM 1995. Nematóides do Brasil. Parte IV: nematóides de aves. Rev Bras Zool 12 (Supl. 1): $1-273$.

Zander DV, Bermudez AJ, Mallinson ET 1997. Principles of disease prevention: diagnosis and control. In BW Calnek, HJ Barnes, CW Beard, LR McDougald, YM Saif (eds), Diseases of Poultry, 10th ed., Iowa State University Press, Ames, p. 3-45.

Zuchowska E 1994. Niektore choroby pasozytnicze golebi. Mag Weterynar 3: 30-31. 